\title{
Incretins and microRNAs: interactions and physiological relevance
}

Shabnam Radbakhsh, ${ }^{1}$ Thozhukat Sathyapalan, ${ }^{2}$ Maciej Banach, ${ }^{3,4}$ Amirhossein Sahebkar ${ }^{5,6,7 *}$

${ }^{1}$ Department of Medical Biotechnology, Mashhad University of Medical Sciences, Mashhad, Iran. ${ }^{2}$ Department of Academic Diabetes, Endocrinology and Metabolism, Hull York Medical School, University of Hull, Hull HU3 2JZ, UK

${ }^{3}$ Department of Hypertension, WAM University Hospital in Lodz, Medical University of Lodz, Zeromskiego 113, Lodz, Poland

${ }^{4}$ Polish Mother's Memorial Hospital Research Institute (PMMHRI), Lodz, Poland

${ }^{5}$ Biotechnology Research Center, Pharmaceutical Technology Institute, Mashhad University of Medical Sciences, Mashhad, Iran.

${ }^{6}$ Neurogenic Inflammation Research Center, Mashhad University of Medical Sciences, Mashhad, Iran.

${ }^{7}$ School of Pharmacy, Mashhad University of Medical Sciences, Mashhad, Iran.

\section{*Corresponding author:}

- Amirhossein Sahebkar, PharmD, PhD, Department of Medical Biotechnology, School of Medicine, Mashhad University of Medical Sciences, Mashhad, Iran, P.O. Box: 91779-48564, Iran. Tel: 985118002288; Fax:985118002287; E-mail: sahebkara@mums.ac.ir; amir_saheb2000@yahoo.com

Running Title: Incretins and microRNAs

Conflict of interests: None

(C2020. This manuscript version is made available under the CC-BY-NC-ND 4.0 license http://creativecommons.org/licenses/by-nc-nd/4.0/ 


\begin{abstract}
MicroRNAs (miRNA) are one class of the small regulatory RNAs that can impact the expression of numerous genes including incretin hormones and their $\mathrm{G}$ protein-coupled receptors. Incretin peptides, including GLP-1, GLP-2, and GIP, are released from the gastrointestinal tract and have an crucial role in the glucose hemostasis and pancreatic beta-cell function. These hormones and their analogs with a longer half-life, glucagon like peptide-1 receptor agonists (GLP1RA), modify the expression of miRNAs. Dipeptidyl peptidase IV (DPP-4) is an enzyme that degrades the incretin hormones and is inactivated by DPP-4 inhibitors, which are a class of compounds used in the management of type 2 diabetes. DPP-4 inhibitors may also increase or reduce the expression of miRNAs. In this review, we describe the possible interactions between miRNAs and incretin hormones and the relevance of such interactions to physiological processes and diseases.
\end{abstract}

Keywords: miRNAs; incretin; GLP1-R; incretin receptor agonist; DPP-4 inhibitor 


\section{Introduction}

Gene expression can be modulated in different levels of the protein production process from the initiation (transcription) to the end (post-translational modification), particularly in the eukaryotic cells by several regulatory factors [1]. MicroRNAs (miRNA) are short noncoding RNAs that contain 18-22 nucleic acids that are encoded by their genes within the genome. These regulators bind to 3 UTR of mature messenger RNA (mRNA) and have an essential role in RNA silencing through the RNA-induced silencing complex (RISC) (Fig.1) [2]. In this review, we describe the effects of miRNAs on the expression of incretin hormones and their effect on various metabolic processes. Certain miRNAs reduce the expression of gut-derived peptide hormones, especially glucagon-like peptide-1 (GLP-1), and may impair glucose homeostasis along with beta-cell dysfunction associated with diabetes. In addition, miRNAs affect the incretin receptors as well. Glucagon-like peptide-1 receptor (GLP-1R) is a receptor belonging to the G-protein family and is involved not only with glucose homeostasis but also with neuroprotection and memory [3]. Incretins are peptides derived from the gastrointestinal family of hormones that have a crucial role in various metabolic functions, including lipoprotein metabolism and lipid accumulation, antiinflammatory effect on the immune system and glucose homeostasis [4-7]. Due to the different mechanisms by which these molecules induce insulin sensitivity and secretion besides reducing the glucagon secretion, they are considered as one of the important therapeutic agents in the management of diabetes [8]. The incretin peptides are influenced by the miRNAs, however, incretin hormones may regulate miRNAs expression as well. Studies have shown that most of these up- and down-regulation effects of incretins are related to the lipid and glucose metabolism. The GLP1R agonists or incretins are now considered as mainline therapy for the management of type 2 diabetes (T2D) [9]. It has been shown that GLP1R agonists have an effect on the expression 
of miRNAs and are considered as a regulator for both increasing and decreasing the level of miRNA expression.

Dipeptidyl peptidase 4 (DPP-4) is an enzyme that degrades the incretin hormones. The DPP-4 inhibitors block the action of DPP-4 and reduce the blood glucose by increasing half-life of gutderived peptides [8]. The last section of this review describes the relationship between DPP-4 inhibitors and expression of various miRNAs.

\section{Effects of miRNAs in regulating incretin hormones}

The miRNA molecules are small, non-coding RNAs containing about 22 nucleic acids that have emerged as a gene expression regulator in the past decade [10]. Several studies indicate that along with their regulatory roles, miRNAs also can be used both as biomarkers and therapeutic targets for various diseases $[11,12]$. Like many proteins and peptides, the expression of incretins may be influenced by RNA interference, particularly miRNAs that can alter biological processes (Table 1). Some miRNAs have a stimulatory role in the expression of incretin hormones and increase the secretion of GLP-1 $[13,14]$. One study suggested that lipid A (or endotoxin) can reduce the risk of T2D by improving the pancreatic $\beta$-cell function. Lipopolysaccharide (LPS) upregulates both interleukin (IL)-6 expression and miR-155 that promote insulin secretion, increase GLP-1 production and suppress V-maf avian musculoaponeurotic fibrosarcoma oncogene homolog B (Mafb). The miR-155 increases IL-6 secreted from the $\beta$-cell by which pancreatic cells have more tendencies to produce GLP1 towards glucagon hormones [13]. Another study showed that alterations in the composition of gut microbiota by fructooligosaccharides (FOS) changed the host gene expression. FOS is a non-digestible oligosaccharide composed of fructose units and has beneficial physiological effects, such as decreasing the levels of serum cholesterol and 
triacylglycerols, low sweetness intensity, and is used as a prebiotic agent. Fermentable dietary FOS decreased miR-33 expression in the liver, thereby increasing the production of GLP-1 hormone and improving insulin sensitivity [14].

In contrast, several miRNAs reduce the incretin levels and can play a role in the development of diabetes. Pan and colleagues in 2017, demonstrated that miR-192 promoted type 1 diabetes (T1D) in the patients by suppressing the expression of GLP-1 and reducing the secretion of insulin. Moreover, overexpression of miR-192 not only inhibited cell proliferation but also facilitated apoptosis in the pancreatic $\beta$ cell, although the exact mechanism of action is unclear [15]. The reduction of incretin hormones mediated by miRNAs may also occur following a disease. For instance, pancreatic cancer (PC) is associated with diabetes mellitus, although the exact mechanism is not yet been fully elucidated. PC-derived exosomes upregulated miRNAs (miR6796-3p, miR-6763-5p, miR-4750-3p and miR-197-3p) by which the expression of incretin hormones was remarkably reduced. Downregulation of GLP-1 and glucose-dependent insulinotropic polypeptide (GIP) resulted in the suppression of proprotein convertase subtilisin/kexin (PCSK)1/3 and PCSK2, which are essential enzymes that are required for the posttranslational processing [16].

The gut microbiota (GM) dysbiosis involves different miRNA target genes related to the cholesterol and glucose metabolism. Considering these changes were tissue-specific, in colon-2W, downregulation of miR-1955-5p and upregulation of miR-466n-3p, miR-1197-3p, miR-6356, miR-875-5p, miR-7679-5p, and miR-542-3p enhanced the expression of ADCY6 and KCNN1 genes, which are related to the GLP1 secretion. Therefore, dysbiotic GM disturbs the glucose hemostasis by reducing the GLP1 mediated insulin signaling pathways and insulin sensitivity in the colon and liver [17]. 
miRNAs also can have a dual role as a regulator and suppressor in the incretin expression. Knudsen and coworkers in 2015 explained the crucial role of miRNAs in the enteroendocrine differentiation and development; moreover, they described several miRNAs expressed when the cells commit to a particular epithelial cell lineage. They found that miR-7b-5p, let-7g-3p, miR-582-3p, and miR375 are upregulated in the mature enteroendocrine cells. Since miR-582 was detected in both CCKeGFP+ enteroendocrine and non-enteroendocrine cells, it may act as a suppressor for stem cells. Among these, miR-375 is highly expressed in all intestinal cells and has a dual role as an inhibitor in the intestinal stem cells of organoid cultures or as a regulator in the mature cells. Furthermore, miR-375 is also required for the glucose-regulated insulin secretion by maintaining the beta-cell mass and their function [18]. As described above, miRNAs may have regulatory effects (upand down-regulation) on incretin hormone expression that have an essential role in developing metabolic diseases such as diabetes (Fig.2).

\section{2. miRNAs and expression of incretin receptors}

Incretins are released after meals and affect the pancreatic cells when they bind to their receptors. Both GLP and GIP receptors are members of the G protein family that initiate a signaling cascade, thereby increase adenylate cyclase enzyme to produce further cAMP in the pancreatic $\beta$-cells and ultimately stimulate insulin secretion [19]. The miRNAs can modulate the expression of incretin receptors (Table 2), some of which decrease the expression of the GLP-1 receptor. For the first time, an animal study showed that incretin receptors are under the control of miRNAs, and miR204 is capable of binding to 3UTR of GLP1R, thereby inhibited the expression of this receptor significantly. Hence, by blocking the miR-204, the level of GLP1R increased and improved glucose tolerance and insulin secretion [20]. miR-665 reduces the GLP1 receptor expression as well and elevates cell apoptosis via inhibiting GLP1 and cAMP function in heart failure (HF) rats. 
Hence, the downregulation of miR-665 activates the cAMP signaling pathway via binding to GLP1R which represses apoptosis of cardiac cells and consequently improves the cardiac function [21]. Another animal study on miR-338 demonstrated that bisphenol A (BPA) exposure timedependently changed the level of miR-338. Bisphenol A (BPA) is a type of endocrine-disrupting chemical that is used to make plastics products and a variety of common consumer goods. BPA interacts with nuclear receptors; for instance, it can bind to the nuclear estrogen receptors (ERs) like the effects of natural hormones and keep these receptors in the active conformation \{Wei, $2017 \# 164$ \}, besides has been shown that BPA can disorder glucose homeostasis and impair pancreatic islet function. Long-term BPA exposure upregulated the miR-338 thereby suppressing the GLP1. miR-338 has been associated with GLP1R as well as Pdx 1 expression that is involved in islet $\beta$ cell function and survival, respectively [22]. The expression of miR-338 also decreased during obesity and pregnancy by stimulating the G protein-coupled estrogen receptor (GPR30) and the glucagon-like peptide1 receptor (GLP1R) [23]. In a study on two groups of laboratory animals (old and young) showed that miRNA might increase GLP1R by olive oil consumption. They showed that phenolic compounds in olive oil such as oleuropein, oleocanthal, hydroxytyrosol, and tyrosol downregulated miR-27 involved in the control of GLP1R gene expression, thereby reduced anxiety in the old animals. It is noteworthy to mention that GLP1R has a significant role in neuroprotection besides glucose metabolism and insulin secretion [3].

\section{Regulation of miRNA expression by incretins}

Incretin hormones are gut-derived peptides, which stimulate insulin secretion pathway by binding to G-protein coupled receptors present on the surface of pancreatic beta cells and other tissues [9]. GLP-1 and GIP are the most prominent members in this family of hormones that are secreted by 
the gastrointestinal tract. Intestinal enteroendocrine L-cells located in the ileum and colon produce glucagon-like peptide-1(GLP-1) and glucagon-like peptide-2(GLP-2), whereas glucose-dependent insulinotropic polypeptide (GIP) are released from the K-cells in the duodenum (Fig.3) [24]. These hormones both down- and up-regulate miRNAs that might affect gene expression (Table 3) [25]. GLP-1 is a peptide with a very short half-life composed of 31 amino acids. This hormone has several pharmacological effects that ameliorate hyperglycemia by increasing insulin secretion and insulin sensitivity as well (Fig.4), reducing oxidative stress [8]. Studies have shown that alteration of GLP-1 can affect the expression of some miRNAs. Therefore, any natural, semi-synthetic, and synthetic compounds that will increase the amount of GLP1 may lead to the modification of expression of miRNAs. GLP-1 peptides have an inhibitory effect on the expression of certain miRNAs. Four of such miRNAs are miR-758, miR-27a, miR-192, and miR-23a have been shown to induce ATP-binding cassette transporter (ABCA1) protein and thereby regulate lipid homeostasis and inhibit the hepatocyte apoptosis [26-29]. Yao et al. in 2018 reported the correlation between GLP1 and cholesterol-induced apoptosis. They found that GLP1 can ameliorate the lipid abnormalities associated with $\mathrm{T} 2 \mathrm{D}$ by downregulating miR-758 and enhancement of ABCA1. This protein is necessary for the control of cholesterol homeostasis; however, the exact mechanism is still not clear [26]. They have also showed in another study that the positive effect of GLP1 on cholesterol accumulation and improved $\beta$-cells dysfunction through the reduction of miR-27a, which results in increased expression of ABCA1 protein and modulation of intracellular cholesterol hemostasis [27]. Downregulation of miR-192 improved lipid metabolism and attenuated total cholesterol through a similar mechanism [28]. The downregulation of miR-23 by GLP1 leads to a reduction of apoptosis of hepatocyte G2 cells by inducing mitochondrial protective gene PGC-1a. The expression of uncoupling protein 2 (UCP2) 
was increased, thereby reducing apoptotic death and increased cell survival in response to GLP1 [29].

The cAMP is a second messenger responsible for multiple physiological functions in living cells. Some natural or synthetic compounds can increase the synthesis of cAMP from ATP. Forskolin is a plant derived compound with diverse pharmacological effects that increases the cellular cAMP concentration by stimulating adenylyl cyclase enzyme which is involved in the glucose and lipid mechanism. cAMP is regulated by the transcription factor cAMP-responsive element-binding protein (CREB), which binds to diverse miRNAs such as miR-212 and miR-132. Malm, H.A. and coworkers in 2015 demonstrated that the overexpression of miR-212 and miR-132 by enhancement of cAMP in response to GLP1 and forskolin could augment the insulin secretion and improve the $\beta$ cells function. [30, 31]. GLP2 is another incretin hormone made up of 33 amino acids that are released from the L cells and can improve the function of hepatocytes by regulating glucose and lipid metabolism [32]. GIP, a 42-amino-acid peptide, has a significant role in various physiological processes as well [19]. Yan et al. in 2017 demonstrated that an oral glucose tolerance test (OGTT) increased the glucagon-like peptide-1 (GLP-1), glucagon-like peptide-2 (GLP-2) and glucose-dependent insulinotropic polypeptide (GIP) that lead to overexpression of miR-375. This circulating miR is not released in the serum and liver abundantly, but a moderate expression was detected in the brain and CSF. Therefore, in response to incretin peptides secretion, several endocrine cell types express miR-375 with a diverse effect on lipid and glucose metabolism in the liver. In this study, the level of miR-375 increased after the administration of oral glucose and enhanced the incretin level. The GLP2 following nutrient uptake increases the level of miR-375 and improves lipid and glucose metabolism. In contrast, knock out mir-375 results in reduced $\beta$ cell mass and hyperglycemia [33]. 


\section{Modification of miRNAs by incretin receptor agonists}

GLP-1R agonists (e.g., liraglutide \& exendin-4) are incretin mimetics, which are used in the management of type 2 diabetes. There is growing evidence that GLP-R agonists can regulate the expression of various miRNAs (Tables 4 and 5).

4.1. Liraglutide is an acylated human GLP-1 analogue, which has a protective effect on various tissues. Li et al. in 2016 investigated whether the antiapoptotic effect of liraglutide is due to the downregulation of miR-139-5p. Real-time quantitative RT-PCR results showed that treatment with liraglutide on cells resulted in the enhancement of mRNA and insulin receptor substrate-1 (IRS1) protein by attenuating miR-139. The TUNEL and annexin V/propidium iodide staining demonstrated a reduction of apoptosis in the pancreatic tissue from diabetic rats [34]. The beneficial effect of liraglutide on pancreatic islet can enhance apoptosis in pancreatic $\alpha$-cells by inhibiting the cAMP-PKA signal pathway and had an opposite effect in pancreatic $\beta$-cells as previously mentioned for GLP1, GLP2, and GIP, thereby increasing the cell viability [35].

The protective effect of liraglutide on bones was studied in patients with diabetes. The expression of let-7c-2-3p, let-7a-1-3p, and miR-322-3p was more in patients with diabetes that was reduced by liraglutide treatment. The above-mentioned miRNAs blocked the expression of $\mathrm{Wnt} / \beta$-catenin pathway genes, suggesting that liraglutide has a potential beneficial effect on metabolic bone disorders [36]. Liraglutide has vasoprotective effects by improving endothelial function by inhibiting miR-181a-5p, miR-93-5p, and miR-34a 5p expression as well as increasing the miR26a-5p expression. PTEN is a miR-26a-5p target gene, whereas Creb is a miR-181a-5p target, both of which control the balance between survival and death in various cell lines such as vascular 
endothelial cells. Indeed, miRNA alteration by liraglutide could inhibit endothelial cell apoptosis via activating the PI3K-AKT-Bcl-2 pathway [37].

Studies show that in addition to beneficial effects on glucose homeostasis, lipid metabolism is also influenced by liraglutide. When the effects of liraglutide to prevent the development of nonalcoholic fatty liver disease (NAFLD) was investigated, it was shown that miR-124 could degrade adipose triglyceride lipase (ATGL) mRNA by binding to the 3UTR region. Liraglutide enhanced the ATGL and Sirtuin1 expression resulting in reduced lipid accumulation and inflammation in cells [38]. In another study, liraglutide through miR 192-5p attenuated lipid accumulation by reducing stearoyl-CoA desaturase 1 (SCD-1) [39]. Shen et al. investigated the alteration of miRNA expression in nonalcoholic fatty liver disease (NAFLD) (36). They showed that the expression of miR-34a, miR-21, miR-451 increased, whereas the expression of miR-183 was decreased in an animal model with hepatic steatosis. miRNA next-generation sequencing results revealed that liraglutide decreased these miRNAs levels that are related to lipid metabolism, regulation of cell apoptosis, and oxidative stress response [40]. Eventually, the anti-breast cancer potential of liraglutide was reported by Zhao and colleagues in 2017, where they showed a dosedependent effect of liraglutide in patients with TD2 and breast cancer. miR-27 is highly expressed in many cancers, including breast cancer, and thereby the expression of AMP-activated protein kinase catalytic subunit $\alpha 2$ (AMPK $\alpha 2$ ) was reduced. Treatment with liraglutide had a reverse effect on the miR-27 expression, increased AMPK $\alpha 2$ protein, and consequently suppressed cell proliferation in breast cancer [41].

4.2- Exenatide is another GLP1-R agonist and is used as an anti-diabetic medication for the management of T2D that can modulate the expression of miRNAs [Table 5]. The pharmacological 
effects of exenatide influence multiple organs and tissues, including the pancreas, heart and kidneys by modulating different metabolic pathways. With regards to pancreatic $\beta$-cells, Exendin4 downregulates miR-375 through blocking its promotor mediated cAMP-protein kinase A (PKA) pathway. Since miR-375 has a negative effect on insulin secretion, treatment with Exendin-4 increases the insulin response in pancreatic $\beta$-cells [42]. In high-fat diet (HFD) mice, Exendin-4 modulated miR-7, miR-9 and miR-375. The expression of miR-7 decreased significantly, the expression of mTOR increased and improved beta cells proliferation after treatment with a high dose of Exendin-4, but no differences were seen in a low dose of Exendin-4 treatment. miR-375 also reduced with both high or low doses of Exendin-4 and its expression associated with stimulation of PDK-1, thereby beta cells function and insulin secretion increased. The miR-9 showed similar results to miR-375 with a reduction of miR-9 at both high and low doses of Exendin-4 with improvement in GSIS and $\beta$-cell function [43]. A similar study compared the expression pattern of miRNAs in exendin 4 treatment mice at three (high, middle and low) doses with a control group. Real-time fluorescent quantitative PCR demonstrated a reduction of miR19a, miR-19b, and miR-22 and an increase of miR-1 expression. These four distinct miRNA-target genes are related to glucose metabolism, cell proliferation and apoptosis; hence significant alterations were observed on blood glucose and pancreatic tissue. No atrophy or hypertrophy besides reducing the degree of fibrosis in pancreatic tissue was observed during histopathological analysis, thereby confirming the effective role of exendin-4 in promoting insulin secretion and protecting against pancreatic injury in diabetes [44].

It has been shown that time-dependent bisphenol A (BPA) exposure can alter the expression of miRNAs. Short term exposure of (BPA) reduced the level of mir-338 via stimulating G proteincoupled estrogen receptor 1 (GPR30) and long-term exposure upregulate miR-338 by repressing 
glucagon-like peptide1 receptor (GLP1R). Bisphenol A reduced miR-338-pdx1, decreased ATP synthesis and insulin secretion in islets. After this BPA exposed cells when treated with exendin4 compensated for the defect of miR-338 and BPA in islet cells [22].

Lee and colleagues in 2015, assessed alteration of miRNAs level after exenatide treatment in an HFD-induced mouse model of obesity. Exenatide attenuated the expression of miRNA-15a, $124 \mathrm{a}, 29 \mathrm{c}$, and 375 in the pancreas along with miRNA-29c, 124a, and 146a in the liver, and eventually increased 15a, 29c, 124a, and 375 levels in serum. They concluded that improvement of insulin sensitivity with exenatide was related to the expression of miRNA-15a, 29c, 124a, and 375 [45]. Apart from the positive effect of Exendin-4, Sun et al. investigated its role in the development of pancreatitis. miR-181, miR-148, miR-210 and miR-216a are considered as potential biomarkers for pancreatitis and with Exenatide treatment, no differences were found in the expression of relevant miRNAs with pancreatitis [46]. Exendin-4 has a positive effect on diabetic kidney disease (DKD) through the miR-192-GLP1R pathway. Exendin-4 decreases the expression of miR-192 and enhances the GLP-1 receptor level, which can ameliorate renal fibrosis [35]. Niu and colleagues in an animal study showed that Exendin-4 had a beneficial effect on the redox homeostasis in HFD rats. They found that Exendin-4 treatment decreased miR-376c expression in the HFD liver and enhanced the hepatic cystathionine- $\beta$-synthase (CBS) protein and GSH levels, thereby reducing the malondialdehyde level in these hyperlipidemic rats. Exendin-4 did not influence the expression level of miR-376c in HepG2 cells and was reported only in the livers of rats fed with HFD [47].

Concerning the effect of exenatide on cardiac function, Sassoon and coworkers investigated the impact of Exendin-4 in cardiac response to ischemia and reperfusion in swine as a larger animal model. They found that Exendin-4 treatment prevented the downregulation of miRs 378, 423-3p, 
133a-5p, 361-3p, and 423-5p in lean swine during ischemia whereas enhanced expression of miR491 and miR-146a in obese swine.

The role of GLP1 and exendin-4 in maintaining pluripotency in hematopoietic stem cells was investigated by Chayosumrit and coworkers in 2011. They found that the exendin-4 treatment effect during human embryonic stem cells (hESC) differentiation measured by quantitative realtime PCR (qPCR) resulted in significant upregulation of miR-302a and miR-302c besides repression of SOX17 and FOXA2 expression. miR-302 families are crucial miRNAs to maintain self-renewal and hESC pluripotency [48].

\section{DPP-4 inhibitors can modulate miRNAs expression}

Dipeptidyl peptidase IV (DPP-4), also known as CD26 is a surface antigen with enzymatic action that is encoded by the DPP4 gene and expressed on the diverse range of human cells particularly on the surface of epithelial cells and biological fluids. This protein degrades the incretin hormones and converts to their inactive natural form. Despite their short half-life and rapid cleavage, these gut hormones have a crucial role in regulating and controlling blood glucose. DPP-4 inhibitors are a class of anti-diabetic medications used to treat T2D via suppressing the DPP4 enzyme [49]. Besides these anti-diabetic effects, these therapeutic agents modify miRNAs expression resulting in various other metabolic effects [Table.6]. Birnbaum and coworkers compared linagliptin (a DPP-4i inhibitor) with exendin-4 (GLP1 receptor agonist) in cardiac dysfunction and inflammation. They found that both linagliptin and exendin-4 reduce the infarct size ischemiareperfusion animal models. Linagliptin also attenuated inflammation in patients with T2D through the suppression of the Nlrp3/ASC inflammasome and Toll-like receptor 4 (TLR4) expression mediated by various miRNAs. The upregulation of Let-7i and miR-146b by linagliptin treatment 
activates p38, thereby reducing the inflammation and increasing the expression of collagen- 1 and collagen-3 mainly via the action of miR-146 [50]. Renal fibrosis and resultant renal failure are some of the most typical complications in patients with diabetes. Kanasaki and colleagues demonstrated that linagliptin, a DD4- inhibitor, improved renal fibrosis in diabetic mice mediated by miR-29. miRNA array analysis showed that linagliptin induced the expression of miRNA 29 by which TGF-b2-induced endothelial-to mesenchymal transition (EndMT) was suppressed. The antifibrotic effects of linagliptin are correlated with TGF-b1 and suppression of DPP-4 [51]. Overexpression of miR-200b results in 200-c modified lipid accumulation and fatty acid synthase (FAS) by inducing the expression of JUN gene and sterol regulatory element-binding protein 1 (SREBP1) activation. In contrast, suppression of miRNA 200 increased triglyceride levels. Sitagliptin (DPP-4 inhibitor) might have a positive effect in reducing hepatic lipid accumulation associated with enhancing expression of miR-200 [52].

\section{Conclusion}

Incretins are peptides released from the intestine, which have an effect on the pancreatic cells. miRNAs are small noncoding RNAs that bind to the 3'UTR region of mature mRNA and modify the gene expression mediated by the RISC complex, some of which can regulate the action of incretin hormones. Some miRNAs, including miR-155-5p and miR-33, increase the expression of incretin hormones, particularly GLP-1, thereby stimulating insulin secretion from pancreatic beta cells. On the contrary, miR-192, miR-6763, miR-197, miR-466n-3p, miR-1197-3p, miR-6356 and miR-875-5p downregulate the incretin expression and disturb the insulin secretion pathway. These miRNAs may have a dual role in controlling gene expression by both up or downregulation in different tissues like miR-375. miRNAs also modify incretin receptors. miR-204, miR-665 and 
miR-338 suppress the GLP1-R expression, whereas miR-27a stimulates the GLP1-R in the cerebral cortex. The incretin hormones can also modulate the expression of miRNAs. GLP1 upregulates miR-758, miR-27a, miR-192, miR-212 and miR-132 but downregulates miR-23 and miR-375. Both up and downregulation result in a reduction of blood glucose by improving betacell function and increasing insulin secretion. There is growing evidence on the effect of medications for the treatment of diabetes linked with these peptide hormones such as GLP1R agonists and DPP-4 inhibitors that affect the expression of various miRNAs. Further experimental researches are warranted to fully elucidate these pathways, which are potential biomarkers and therapeutic targets.

Conflict of interests: Dr. Banach has served on the speakers bureau of Abbott/Mylan, Abbott Vascular, Actavis, Akcea, Amgen, Biofarm, KRKA, MSD, Sanofi-Aventis, Servier and Valeant, and has served as a consultant to Abbott Vascular, Akcea, Amgen, Daichii Sankyo, Esperion, Lilly, MSD, Resverlogix, Sanofi-Aventis; Grants from Sanofi and Valeant. Other authors have no competing interests to declare. 


\section{References}

[1] J.H. Gibcus, J. Dekker, The context of gene expression regulation, F1000 Biol Rep 4 (2012) 8.

[2] C. Catalanotto, C. Cogoni, G. Zardo, MicroRNA in Control of Gene Expression: An Overview of Nuclear Functions, Int J Mol Sci 17(10) (2016).

[3] C. Luceri, E. Bigagli, V. Pitozzi, L. Giovannelli, A nutrigenomics approach for the study of anti-aging interventions: olive oil phenols and the modulation of gene and microRNA expression profiles in mouse brain, Eur J Nutr 56(2) (2017) 865-877.

[4] J.E. Campbell, D.J. Drucker, Pharmacology, physiology, and mechanisms of incretin hormone action, Cell Metab 17(6) (2013) 819-37.

[5] M. Rizzo, D. Nikolic, M. Banach, A.M. Patti, G. Montalto, A.A. Rizvi, Incretin-based therapies, glucometabolic health and endovascular inflammation, Curr Pharm Des 20(31) (2014) 4953-60.

[6] M. Rizzo, N. Abate, M. Chandalia, A.A. Rizvi, R.V. Giglio, D. Nikolic, A. Marino Gammazza, I.

Barbagallo, E.R. Isenovic, M. Banach, G. Montalto, G. Li Volti, Liraglutide reduces oxidative stress and restores heme oxygenase-1 and ghrelin levels in patients with type 2 diabetes: a prospective pilot study, J Clin Endocrinol Metab 100(2) (2015) 603-6.

[7] A.A. Rizvi, A.M. Patti, R.V. Giglio, D. Nikolic, A. Amato, N. Al-Busaidi, K. Al-Rasadi, M. Soresi, M. Banach, G. Montalto, M. Rizzo, Liraglutide improves carotid intima-media thickness in patients with type 2 diabetes and non-alcoholic fatty liver disease: an 8-month prospective pilot study, Expert Opin Biol Ther 15(10) (2015) 1391-7.

[8] H. Yaribeygi, T. Sathyapalan, A. Sahebkar, Molecular mechanisms by which GLP-1 RA and DPP-4i induce insulin sensitivity, Life Sci 234 (2019) 116776.

[9] S.L. Samson, A. Garber, GLP-1R agonist therapy for diabetes: benefits and potential risks, Curr Opin Endocrinol Diabetes Obes 20(2) (2013) 87-97.

[10] S. Vienberg, J. Geiger, S. Madsen, L.T. Dalgaard, MicroRNAs in metabolism, Acta Physiol (Oxf) 219(2) (2017) 346-361.

[11] A. Latini, P. Borgiani, G. Novelli, C. Ciccacci, miRNAs in drug response variability: potential utility as biomarkers for personalized medicine, Pharmacogenomics 20(14) (2019) 1049-1059.

[12] A. Sliwinska, M.A. Kasinska, J. Drzewoski, MicroRNAs and metabolic disorders - where are we heading?, Arch Med Sci 13(4) (2017) 885-896.

[13] M. Zhu, Y. Wei, C. Geissler, K. Abschlag, J. Corbalan Campos, M. Hristov, J. Mollmann, M. Lehrke, E. Karshovska, A. Schober, Hyperlipidemia-Induced MicroRNA-155-5p Improves beta-Cell Function by Targeting Mafb, Diabetes 66(12) (2017) 3072-3084.

[14] B.D. Pachikian, A. Essaghir, J.B. Demoulin, E. Catry, A.M. Neyrinck, E.M. Dewulf, F.M. Sohet, L.

Portois, L.A. Clerbaux, Y.A. Carpentier, S. Possemiers, G.T. Bommer, P.D. Cani, N.M. Delzenne, Prebiotic 
approach alleviates hepatic steatosis: implication of fatty acid oxidative and cholesterol synthesis pathways, Mol Nutr Food Res 57(2) (2013) 347-59.

[15] W. Pan, Y. Zhang, C. Zeng, F. Xu, J. Yan, J. Weng, miR-192 is upregulated in T1DM, regulates pancreatic beta-cell development and inhibits insulin secretion through suppressing GLP-1 expression, Exp Ther Med 16(3) (2018) 2717-2724.

[16] Y. Zhang, S. Huang, P. Li, Q. Chen, Y. Li, Y. Zhou, L. Wang, M. Kang, B. Zhang, B. Yang, X. Dong, Y. Wu, Pancreatic cancer-derived exosomes suppress the production of GIP and GLP-1 from STC-1cells in vitro by down-regulating the PCSK1/3, Cancer Lett 431 (2018) 190-200.

[17] L. Deng, R. Wang, H. Li, C. Zhang, L. Zhao, M. Zhang, miRNA-Gene Regulatory Network in Gnotobiotic Mice Stimulated by Dysbiotic Gut Microbiota Transplanted From a Genetically Obese Child, Front Microbiol 10 (2019) 1517.

[18] L.A. Knudsen, N. Petersen, T.W. Schwartz, K.L. Egerod, The MicroRNA Repertoire in Enteroendocrine Cells: Identification of miR-375 as a Potential Regulator of the Enteroendocrine Lineage, Endocrinology 156(11) (2015) 3971-83.

[19] Y. Seino, M. Fukushima, D. Yabe, GIP and GLP-1, the two incretin hormones: Similarities and differences, J Diabetes Investig 1(1-2) (2010) 8-23.

[20] S. Jo, J. Chen, G. Xu, T.B. Grayson, L.A. Thielen, A. Shalev, miR-204 Controls Glucagon-Like Peptide 1 Receptor Expression and Agonist Function, Diabetes 67(2) (2018) 256-264.

[21] B. Lin, D.G. Feng, J. Xu, microRNA-665 silencing improves cardiac function in rats with heart failure through activation of the cAMP signaling pathway, J Cell Physiol 234(8) (2019) 13169-13181.

[22] J. Wei, D. Ding, T. Wang, Q. Liu, Y. Lin, MiR-338 controls BPA-triggered pancreatic islet insulin secretory dysfunction from compensation to decompensation by targeting Pdx-1, Faseb j 31(12) (2017) 5184-5195.

[23] C. Jacovetti, A. Abderrahmani, G. Parnaud, J.C. Jonas, M.L. Peyot, M. Cornu, R. Laybutt, E. Meugnier, S. Rome, B. Thorens, M. Prentki, D. Bosco, R. Regazzi, MicroRNAs contribute to compensatory beta cell expansion during pregnancy and obesity, J Clin Invest 122(10) (2012) 3541-51.

[24] R. Gutierrez-Aguilar, S.C. Woods, Nutrition and L and K-enteroendocrine cells, Curr Opin Endocrinol Diabetes Obes 18(1) (2011) 35-41.

[25] B. Kura, M. Parikh, J. Slezak, G.N. Pierce, The Influence of Diet on MicroRNAs that Impact Cardiovascular Disease, Molecules 24(8) (2019).

[26] Y. Yao, Q. Li, P. Gao, W. Wang, L. Chen, J. Zhang, Y. Xu, Glucagon-like peptide-1 contributes to increases ABCA1 expression by downregulating miR-758 to regulate cholesterol homeostasis, Biochem Biophys Res Commun 497(2) (2018) 652-658.

[27] Y. Yao, Y. Xu, W. Wang, J. Zhang, Q. Li, Glucagon-like peptide-1 improves beta-cell dysfunction by suppressing the miR-27a-induced downregulation of ATP-binding cassette transporter A1, Biomed Pharmacother 96 (2017) 497-502.

[28] Y. Yao, Q. Li, W. Wang, J. Zhang, P. Gao, Y. Xu, Glucagon-Like Peptide-1 Modulates Cholesterol Homeostasis by Suppressing the miR-19b-Induced Downregulation of ABCA1, Cell Physiol Biochem 50(2) (2018) 679-693.

[29] C. Wang, Q. Li, W. Wang, L. Guo, C. Guo, Y. Sun, J. Zhang, GLP-1 contributes to increases in PGC1alpha expression by downregulating miR-23a to reduce apoptosis, Biochem Biophys Res Commun 466(1) (2015) 33-9.

[30] J. Shang, J. Li, M.P. Keller, H.E. Hohmeier, Y. Wang, Y. Feng, H.H. Zhou, X. Shen, M. Rabaglia, M. Soni, A.D. Attie, C.B. Newgard, N.A. Thornberry, A.D. Howard, Y.P. Zhou, Induction of miR-132 and miR-212 Expression by Glucagon-Like Peptide 1 (GLP-1) in Rodent and Human Pancreatic beta-Cells, Mol Endocrinol 29(9) (2015) 1243-53. 
[31] H.A. Malm, I.G. Mollet, C. Berggreen, M. Orho-Melander, J.L. Esguerra, O. Goransson, L. Eliasson, Transcriptional regulation of the miR-212/miR-132 cluster in insulin-secreting beta-cells by cAMPregulated transcriptional co-activator 1 and salt-inducible kinases, Mol Cell Endocrinol 424 (2016) 23-33. [32] A. Amato, S. Baldassano, F. Mule, GLP2: an underestimated signal for improving glycaemic control and insulin sensitivity, J Endocrinol 229(2) (2016) R57-66.

[33] X. Yan, Z. Wang, S. Westberg-Rasmussen, M. Tarbier, T. Rathjen, S.G. Tattikota, B.C.E. Peck, M. Kanke, C. Oxvig, J. Frystyk, J. Starup-Linde, P. Sethupathy, M.R. Friedlander, S. Gregersen, M.N. Poy, Differential Impact of Glucose Administered Intravenously and Orally on Circulating miR-375 Levels in Human Subjects, J Clin Endocrinol Metab 102(10) (2017) 3749-3755.

[34] J. Li, L. Su, Y.Y. Gong, M.L. Ding, S.B. Hong, S. Yu, H.P. Xiao, Downregulation of miR-139-5p contributes to the antiapoptotic effect of liraglutide on the diabetic rat pancreas and INS-1 cells by targeting IRS1, PLoS One 12(3) (2017) e0173576.

[35] Y. Jia, Z. Zheng, M. Guan, Q. Zhang, Y. Li, L. Wang, Y. Xue, Exendin-4 ameliorates high glucoseinduced fibrosis by inhibiting the secretion of miR-192 from injured renal tubular epithelial cells, Exp Mol Med 50(5) (2018) 56.

[36] J. Li, L.Z. Fu, L. Liu, F. Xie, R.C. Dai, Glucagon-Like Peptide-1 (GLP-1) Receptor Agonist Liraglutide Alters Bone Marrow Exosome-Mediated miRNA Signal Pathways in Ovariectomized Rats with Type 2 Diabetes, Med Sci Monit 23 (2017) 5410-5419.

[37] Q. Zhang, X. Xiao, J. Zheng, M. Li, A glucagon-like peptide-1 analog, liraglutide, ameliorates endothelial dysfunction through miRNAs to inhibit apoptosis in rats, PeerJ 7 (2019) e6567.

[38] Q.H. Fang, Q.L. Shen, J.J. Li, Y. Yang, J.J. Guo, Y. Cheng, H.C. Zhou, W.Y. Niu, L.M. Chen, C.J. Li, B. Sun, Inhibition of microRNA-124a attenuates non-alcoholic fatty liver disease through upregulation of adipose triglyceride lipase and the effect of liraglutide intervention, Hepatol Res 49(7) (2019) 743-757. [39] X.-L. Liu, H.-X. Cao, B.-C. Wang, F.-Z. Xin, R.-N. Zhang, D. Zhou, R.-X. Yang, Z.-H. Zhao, Q. Pan, J.-G. Fan, miR-192-5p regulates lipid synthesis in non-alcoholic fatty liver disease through SCD-1, World journal of gastroenterology 23(46) (2017) 8140.

[40] Y. Shen, M. Liu, C. Chen, X. Lai, M. Zhang, MicroRNA profile changes in liraglutide treated steatotic HepG2 cells, Int J Clin Exp Med 10(3) (2017) 4856-4864.

[41] W. Zhao, X. Zhang, Z. Zhou, B. Sun, W. Gu, J. Liu, H. Zhang, Liraglutide inhibits the proliferation and promotes the apoptosis of MCF-7 human breast cancer cells through downregulation of microRNA-27a expression, Mol Med Rep 17(4) (2018) 5202-5212.

[42] D.M. Keller, E.A. Clark, R.H. Goodman, Regulation of microRNA-375 by cAMP in pancreatic $\beta$-cells, Molecular endocrinology 26(6) (2012) 989-999.

[43] C. Guo, Y.Q. Sun, Q. Li, J.C. Zhang, MiR-7, miR-9 and miR-375 contribute to effect of Exendin-4 on pancreatic beta-cells in high-fat-diet-fed mice, Clin Invest Med 41(1) (2018) E16-e24.

[44] J.S. He, C.W. Lian, Y.L. Fang, J.Z. Wu, X.L. Ye, S.B. Zhu, Influence and significance of intervening diabetes microRNA expression profile of NOD mice with exendin-4, Eur Rev Med Pharmacol Sci 20(20) (2016) 4322-4327.

[45] I.S. Lee, K.C. Park, K.J. Yang, H. Choi, Y.S. Jang, J.M. Lee, H.S. Kim, Exenatide reverses dysregulated microRNAs in high-fat diet-induced obese mice, Obes Res Clin Pract 10(3) (2016) 315-26.

[46] K. Tatarkiewicz, P.A. Smith, E.J. Sablan, C.J. Polizzi, D.E. Aumann, C. Villescaz, D.M. Hargrove, B.R. Gedulin, M.G. Lu, L. Adams, Exenatide does not evoke pancreatitis and attenuates chemically induced pancreatitis in normal and diabetic rodents, American Journal of Physiology-Endocrinology and Metabolism 299(6) (2010) E1076-E1086.

[47] S. Niu, L. Wang, M. He, Y. Peng, S. Li, Exendin-4 regulates redox homeostasis in rats fed with high-fat diet, Acta Biochim Biophys Sin (Shanghai) 47(6) (2015) 397-403.

[48] M. Chayosumrit, A.A. Hardikar, K.S. Sidhu, Role of the glucagon-like peptide-1 receptor agonist in maintaining pluripotency in human embryonic stem cells, OPEN STEM CELL JOURNAL eISSN: 1876-8938 
БИБЛИОМЕТРИЧЕСКИЕ ПОКАЗАТЕЛИ: ВХоДИт В РИНЦ ${ }^{\circledR}$ : Да ЦИтИрованИЙ в РИНЦ ${ }^{\circledR}$ : 0 ВходИт в Ядро РИНЦ ${ }^{\circledR}:$ нет Цитирований из ядра РИНЦ ${ }^{\circledR}: 0$ Входит в Scopus ${ }^{\circledR}:$ Цитирований в Scopus ${ }^{\circledR}:$ Входит в Web of Science ${ }^{\circledR}$ : Цитирований в Web of Science ${ }^{\circledR}$ : Норм. цитируемость по журналу: Импакт-фактор журнала в РИНЦ: Норм. цитируемость по направлению: 0 Дециль в рейтинге по направлению: 8 Тематическое направление: Biological sciences 3 (2011) 11-22.

[49] H. Yaribeygi, T. Sathyapalan, A. Sahebkar, Molecular mechanisms by which GLP-1 RA and DPP-4i induce insulin sensitivity, Life sciences (2019) 116776.

[50] Y. Birnbaum, D. Tran, M. Bajaj, Y. Ye, DPP-4 inhibition by linagliptin prevents cardiac dysfunction and inflammation by targeting the NIrp3/ASC inflammasome, Basic research in cardiology 114(5) (2019) 35.

[51] K. Kanasaki, S. Shi, M. Kanasaki, J. He, T. Nagai, Y. Nakamura, Y. Ishigaki, M. Kitada, S.P. Srivastava, D. Koya, Linagliptin-mediated DPP-4 inhibition ameliorates kidney fibrosis in streptozotocin-induced diabetic mice by inhibiting endothelial-to-mesenchymal transition in a therapeutic regimen, Diabetes 63(6) (2014) 2120-2131.

[52] J. Guo, W. Fang, L. Sun, Y. Lu, L. Dou, X. Huang, M. Sun, C. Pang, J. Qu, G. Liu, Reduced miR-200b and miR-200c expression contributes to abnormal hepatic lipid accumulation by stimulating JUN expression and activating the transcription of srebp1, Oncotarget 7(24) (2016) 36207.

[53] D.J. Sassoon, A.G. Goodwill, J.N. Noblet, A.M. Conteh, B.P. Herring, J.N. McClintick, J.D. Tune, K.J. Mather, Obesity alters molecular and functional cardiac responses to ischemia/reperfusion and glucagon-like peptide-1 receptor agonism, Basic Res Cardiol 111(4) (2016) 43. 


\section{Figure legends}

Fig.1. MicroRNAs bind to 3UTR of mature mRNA and modulate gene expression through RISC complex (mRNA silencing) during the processes named post-translational modification.

Fig.2. MicroRNAs regulate incretin expression by which may increase or decrease the probability of developing diabetes mellitus.

Fig.3. The following nutrient uptake, incretin hormones GLP and GIP release from L-cells and K-cells respectively, and by binding to the receptors on the beta cells contribute to insulin secretion. Both of these have a short half-life and rapidly be deactivated by Dipeptidyl peptidase IV (DPP-4).

Fig.4. Effects of GLP-1 peptides on microRNAs expression lead to different mechanisms by which improve beta-cell function. 
Table.1. Effects of miRNAs in regulating incretin hormones and metabolic effects

\begin{tabular}{|c|c|c|c|c|}
\hline miRNA & Function & Detection method & $\begin{array}{c}\text { Experimental } \\
\text { model }\end{array}$ & References \\
\hline $\operatorname{miR}-155-5 p \uparrow$ & $\begin{array}{l}\text { Promote insulin secretion by both } \\
\text { increasing GLP-1 production and } \\
\text { suppressing (Mafb) also induce } \\
\text { defensive mechanism in islet } \\
\text { stress }\end{array}$ & Real-time PCR (qPCR) & $\begin{array}{l}\text { Animal (mice } \\
\text { C57BL/6J) } \\
\text { Cell line (MIN6) }\end{array}$ & [13] \\
\hline $\operatorname{miR}-33 \downarrow$ & $\begin{array}{l}\text { Fructo-oligosaccharides (FOS) } \\
\text { downregulated miR-33 by } \\
\text { which enhanced the production } \\
\text { of GLP-1 hormone and } \\
\text { improved insulin sensitivity }\end{array}$ & qPCR & $\begin{array}{l}\text { Animal (mice } \\
\text { C57BL/6J) }\end{array}$ & {$[14]$} \\
\hline $\operatorname{miR}-192 \uparrow$ & $\begin{array}{l}\text { Induce T1DM by suppressing } \\
\text { the expression of (GLP-1) and } \\
\text { cell proliferation, moreover } \\
\text { facilitate apoptosis in pancreatic } \\
\beta \text { cell }\end{array}$ & qRT-PCR and Western blot & $\begin{array}{l}\text { Animal (SD rat) } \\
\text { Human cell line } \\
\text { (NCI-H716) } \\
\text { Mouse cell line } \\
\text { (NIT-1 } \beta \text { cells) }\end{array}$ & {$[15]$} \\
\hline $\begin{array}{l}\text { miR-6796-3p, miR- } \\
\text { 6763-5p, miR- } \\
\text { 4750-3p and miR- } \\
\text { 197-3p }\end{array}$ & $\begin{array}{l}\text { Downregulation of GIP and } \\
\text { GLP-1 by suppressing } \\
\text { essential enzymes (PCSK1/3 } \\
\text { and PCSK2) }\end{array}$ & Microarray and ELISA & $\begin{array}{l}\text { Cell line (STC-1, } \\
\text { PANC-1, MIA } \\
\text { PaCa-2, and } \\
\text { SW620) }\end{array}$ & {$[16]$} \\
\hline $\begin{array}{c}\text { miR-1955-5p } \downarrow \\
\text { miR-466n-3p/ } \\
\text { miR-1197-3p/ } \\
\text { miR-6356/ miR- } \\
\text { 875-5p/ miR-7679- } \\
\text { 5p/ and miR-542- } \\
\text { 3p } \uparrow\end{array}$ & $\begin{array}{l}\text { GM (gut microbiota) dysbiosis } \\
\text { disturbed GLP1 mediated } \\
\text { insulin signaling pathways by } \\
\text { regulating these microRNAs } \\
\text { that can alter the gene } \\
\text { expression of Adcy6 and Kcnn1 }\end{array}$ & RT-PCR & $\begin{array}{l}\text { Human (PWS } \\
\text { obese child) }\end{array}$ & {$[17]$} \\
\hline $\begin{array}{l}\text { let-7g-3p, miR-7b, } \\
\text { miR-582-3p }\end{array}$ & $\begin{array}{l}\text { were up-regulated in the } \\
\text { enteroendocrine cells } \\
\text { dual role as a regulator and } \\
\text { suppressor also associated } \\
\text { with GLP-1 insulin secretion } \\
\text { pathway }\end{array}$ & qPCR & $\begin{array}{c}\text { Animal } \\
\text { (Transgenic mice } \\
\text { Gpr41-RFP) }\end{array}$ & {$[18]$} \\
\hline
\end{tabular}


Table.2. Effects of miRNAs on incretin hormones secretion and function

\begin{tabular}{|c|c|c|c|c|}
\hline miRNA & $\begin{array}{l}\text { Molecule } \\
\text { (receptor) }\end{array}$ & Function & $\begin{array}{l}\text { Experimental } \\
\text { model }\end{array}$ & References \\
\hline miR-204 & GLPR $\downarrow$ & $\begin{array}{l}\text { Decreased GLP1R expression } \\
\text { significantly, so by blocking miR- } \\
204 \text { improved glucose tolerance and } \\
\text { insulin secretion }\end{array}$ & $\begin{array}{l}\text { Cell line (HEK293) } \\
\text { Animal (mice } \\
\text { C57BL/6J) }\end{array}$ & [20] \\
\hline $\operatorname{miR}-665 \uparrow$ & GLP1R $\downarrow$ & $\begin{array}{l}\text { Suppression of GLP1R expression } \\
\text { and cAMP signaling pathway that } \\
\text { caused cell apoptosis in heart failure }\end{array}$ & Animal (SD rat) & [21] \\
\hline $\operatorname{miR}-338 \uparrow$ & GLP1R $\downarrow$ & $\begin{array}{l}\text { Time dependently BPA exposure } \\
\text { can decrease the expression of GLP- } \\
\text { 1R via increasing miR-338 }\end{array}$ & $\begin{array}{l}\text { Animal (mice } \\
\text { C57BL/6J) }\end{array}$ & [22] \\
\hline $\begin{array}{l}\operatorname{miR-27a-3p} \downarrow \\
\text { (by phenolic } \\
\text { compound) }\end{array}$ & GLP1R $\uparrow$ & $\begin{array}{l}\text { Reduced anxiety in the cerebral } \\
\text { cortex of aged mice }\end{array}$ & $\begin{array}{l}\text { Animal (mice } \\
\text { C57BL/6J) }\end{array}$ & {$[3]$} \\
\hline
\end{tabular}


Table.3. Incretin hormones down or up regulate some microRNA expression

\begin{tabular}{cclll} 
Molecule(incretins) & $\begin{array}{c}\text { Targeted } \\
\text { miRNA }\end{array}$ & \multicolumn{1}{c}{$\begin{array}{c}\text { Function } \\
\text { References }\end{array}$} & $\begin{array}{c}\text { Experimental } \\
\text { model }\end{array}$ \\
\hline GLP-1 & miRNA-758 $\downarrow$ & $\begin{array}{l}\text { Increased ABCA1 expression by } \\
\text { downregulating miR-758 to regulate } \\
\text { cholesterol homeostasis resulting from }\end{array}$ & $\begin{array}{c}\text { Human cell line } \\
\text { GLP1 or cholesterol effect }\end{array}$ \\
& &
\end{tabular}

GLP-1 miR-27a $\downarrow \quad$ May affect cholesterol accumulation and $\beta$-cells dysfunction by regulating the expression ofmiR-27a and ABCA1resulting from GLP1 or

Rat cell line (INS-1

pancreatic $\beta$-cell) cholesterol effect

GLP-1 miR-192 $\downarrow$ Enhanced ABCA1-dependent cholesterol efflux, resulting in reduced total cholesterol

Animal (SD rat)

[28]

Human Cell line (HepG2)

GLP-1 miR-23a $\downarrow$ Increased expression of gene PGC-1a by downregulating miR-23a to inhibit hepatocyte apoptosis and also enhanced UCP2 to reduce apoptosis

Human Cell line (HepG2)
GLP-1 (Forskolin)
miR-212 and miR$132 \uparrow$ in pancreatic $\beta$ cells
Activation of PKA in $\beta$ cells mediated by cAMP elevation can augment glucose and GLP-1 stimulated insulin secretion cell line (INS-1 pancreatic $\beta$-cell)

Animal (mice C57BL/6J) 
Table.4. Effects of Liraglutide on the expression of miRNAs.

\section{Molecule}

(receptor agonist)

\section{miRNA}

(in pancreatic $\alpha$-cells)

\section{Liraglutide}

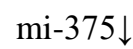

(in pancreatic $\beta$-cells)

\section{Function}

Protected pancreatic $\beta$-cells by inhibiting their apoptosis \& increasing the mRNA and protein levels of IRS1

Increased cell apoptosis by inhibiting the cAMP-PKA signal pathway

\section{Experimental}

model

Animal (SD rat)

Rat cell line

(INS-1 $\beta$-cell)

Human cell line

(HK-2)

Improved cell viability via Activating cAMP-PKA signal pathway references

references 
Table.5. Effect of Exenatide on microRNAs expression

\begin{tabular}{|c|c|c|c|}
\hline $\begin{array}{c}\text { Molecule } \\
\text { (receptor agonist) }\end{array}$ & miRNA & Function & $\begin{array}{l}\text { Experimental references } \\
\text { model }\end{array}$ \\
\hline
\end{tabular}

Exendin-4

$\operatorname{miR}-375 \downarrow$ Increased insulin secretion by $\begin{gathered}\text { Rat cell line } \\ \text { (INS-1 } \beta \text {-cell) }\end{gathered}$
cAMP pathway

(n)

(1)

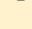

$\begin{array}{ll}\text { miR-7 } \downarrow \downarrow \text { (at high dose) } & \begin{array}{l}\text { Increased expression of mTOR } \\ \text { and induced } \beta \text {-cell } \\ \text { proliferation }\end{array}\end{array}$

no difference in the levels of miR-7 (in low dose)

\section{Exendin-4}

Animal (mice

C57BL/6J)

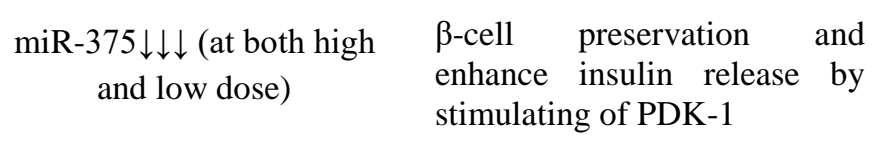
miR-9 $\downarrow \downarrow$ (at both high and low dose)

Regulated gene OC-2 and improved GSIS and $\beta$-cell function

miR-19a, miR-19b, miR-22 $\downarrow$

Exendin-4

miRNA- $1 \uparrow$

Reduced the degree of fibrosis in pancreatic tissue and confirmed protecting effects of Ex-4 in diabetes pancreatic injury

Animal (mice)

Through both mechanisms and mediated miR-338-pdx1 decreased ATP synthesis and insulin secretion in islets

Bisphenol A miR-338 $\downarrow$ (short-term)

Activated GLP-1r to offset

Animal (mice
C57BL/6J)

Bisphenol miR-338个(long-term) miR-338 and BPA effects on islet cell 
miRNA-15a, 124a,29c, and

375 in the pancreas $\downarrow$

Exenatide

miRNA-29c, 124a, and 146a in the liver

Improved insulin sensitivity in a high-fat diet (HFD)-induced

Animal (mice

C57BL/6J)

miRNA-15a, 29c, 124a, \& mouse model of obesity

375 in the serum $\uparrow$

Animal (mice

Exendin-4

miR-181, miR-148, miR-210 and $\mathrm{miR}-216 \mathrm{a}$

No differences were found in C57BL/6J) miRNAs with pancreatitis

$\operatorname{mir} 192 \downarrow$

Exendin-4

Exendin-4

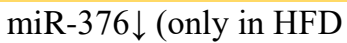
rats' liver)
Improved renal fibrosis by increasing GLP-1 receptor

Human cell line (HK-2)

[35]

Decreased malondialdehyde level and had a beneficial effect on redox homeostasis

Animal (rat)
Exendin-4 Prevent the downregulation of miRs 378,423-3p, 133a5p, 361-3p, and 423-5p in lean swine during ischemia miRs 491, and 146a $\uparrow$ in obese swine
Decreased myocardial infarct size and improved cardiac function
[53]
Maintained pluripotency and inhibited apoptosis in hESCs
Cell line (hESC)

[48] 
Table.6. Effect of DPP-4 inhibitors on the expression of miRNAs

\begin{tabular}{|c|c|c|c|c|}
\hline $\begin{array}{l}\text { Molecule (DDP- } \\
4 \text { inhibitors) }\end{array}$ & miRNA & Function & $\begin{array}{c}\text { Experimental } \\
\text { model }\end{array}$ & References \\
\hline Linagliptin & $\begin{array}{l}\text { Let-7i-3p, Let-7i-5p, } \\
\text { miR-21, and miR-146b } \uparrow\end{array}$ & $\begin{array}{l}\text { Attenuated inflammation in } \\
\text { T2D patient by reducing } \\
\text { TLR4, increasing the } \\
\text { expression of collagen-1 \& } \\
3 \text {, and p38 activation }\end{array}$ & $\begin{array}{l}\text { Animal (mice } \\
\text { C57BL/6J) }\end{array}$ & [50] \\
\hline Linagliptin & miR-29 & $\begin{array}{l}\text { Induced miR } 29 \text { by which } \\
\text { was repressed TGF-B and } \\
\text { DPP-4 and ameliorated } \\
\text { kidney fibrosis }\end{array}$ & $\begin{array}{l}\text { Animal (mice) } \\
\text { Human cell line } \\
\text { (HMVECs) }\end{array}$ & [51] \\
\hline Sitagliptin & $\begin{array}{l}\operatorname{miR} 200 \mathrm{~b} \text { and } \operatorname{miR} 200 \mathrm{c} \uparrow \\
\text { in the liver }\end{array}$ & 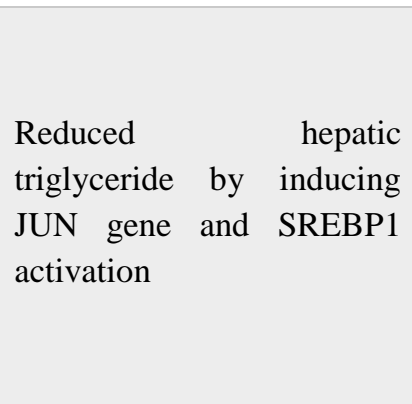 & $\begin{array}{c}\text { Animal (mice } \\
\text { C57BL/6J) } \\
\text { Human (liver } \\
\text { biopsy) } \\
\text { Cell line } \\
\text { (NCTC1469 and } \\
\text { Hep1-6) }\end{array}$ & {$[52]$} \\
\hline
\end{tabular}

